HEALTHCARE DELIVERY

\title{
Safety versus accessibility in maternal and perinatal care
}

\author{
R C Pattinson
}

Bob Pattinson, MD, FRCOG, FCOG (SA), is Director of the Medical Research Council Maternal and Infant Health Care Strategies Unit, Department of Obstetrics and Gynaecology, Faculty of Health Sciences, University of Pretoria, South Africa. His main interests are in implementing effective healthcare interventions at primary and secondary levels of care.

Corresponding author: R C Pattinson (robert.pattinson@up.ac.za)

This article adds to the debate on appropriate staffing in maternity units. My starting point for assessing staffing norms is the staff required to provide a safe maternity unit. A survey in 12 districts showed that their health facilities were not adequately prepared to perform all the essential emergency services required. Lack of staff was often cited as a reason. To test this notion, two norms (World Health Organization (WHO) and Greenfield) giving the minimum staff required for the provision of safe maternity services were applied to the 12 districts. Assuming the appropriate equipment is available and the facility is open 24 hours a day 7 days a week, at a minimum there need to be ten professional nurses with midwifery/advanced midwives to ensure safety for mother and baby in every maternity unit. The norms indicate that the units should do a minimum of 500 - 1200 deliveries per year to be cost-effective. All 12 districts had sufficient staff according to the WHO. When the numbers of facilities with maternity units were compared with Council for Scientific and Industrial Research and WHO norms for number of health facilities per population, a large excess of facilities was found. Per district there were sufficient personnel to perform the number of deliveries for that district using the WHO or Greenfield formulas, but per site there were insufficient personnel. In my view there are sufficient personnel to provide safe maternity services, but too many units are performing deliveries, leading to dilution of staff and unsafe services. A realignment of maternity units must be undertaken to provide safe services, even at the expense of accessibility.

S Afr Med J 2015;105(4):261-265. DOI:10.7196/SAMJ.9182

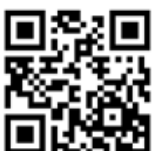

Complications in pregnancy and labour can occur even in the best of circumstances, and a large proportion of serious complications occur among women with no recognisable risk factors at all. ${ }^{[1,2]}$ Most pregnant women in South Africa (SA) ( 60\%) give birth at the primary level of care in community health centres (CHCs) and district hospitals (DHs). Most of the unexpected complications will occur at these levels of care.

To reduce maternal deaths, recognition, stabilisation and treatment or referral of the obstetric emergency must occur at the site closest to where the complication occurred. For the majority of women, this means at CHCs and DHs. Three factors must be present at these sites, namely:

- Healthcare providers with sufficient knowledge and skills to recognise a complication, stabilise and treat or refer the patient

- Healthcare facilities with the essential lifesaving services available, such as in DHs the resources, both human and equipment, to perform caesarean sections (CSs) 24 hours a day, 7 days a week

- An efficient emergency transfer system.

A safe maternity unit is one where the healthcare provider has the knowledge and skills to perform all the observations required on a woman in labour and to manage a complication, either by treatment or by stabilisation and referral. Further, the unit should have sufficient staff to ensure that the woman is monitored appropriately and to deal with the immediate management of complications. Since the maternity services are based on a primary healthcare system where the patient is managed at the lowest appropriate level of care, a mechanism of rapid transport must be available should a complication arise.

An accessible maternity unit is one where patients can reach and receive appropriate care quickly. This usually implies that maternity units must be capable of managing normal pregnancies, with a rapid referral mechanism to higher levels of care where required. Ideally, the maternity units for pregnant women with no identified risk factors are close to the women's homes.
Michalow et al. ${ }^{[3]}$ using the Lives Saved Tool (LiST) estimated that 11562 maternal and perinatal deaths could be averted in 2030 if comprehensive emergency obstetric and neonatal care (CEmONC) was fully implemented. LiST is a module in Spectrum, a demographic software package, which preloads national data for health status, mortality rates, and coverage of more than 60 interventions and their effectiveness in relation to specific causes of death. ${ }^{[4]}$ The modelling methods in LiST have been widely reviewed. ${ }^{[5]}$

The basic emergency obstetric and neonatal care (BEmONC) and CEmONC packages are lists of lifesaving services, or 'signal functions that indicate a health facility's ability to treat obstetric and neonatal emergencies' developed by the World Health Organization (WHO). ${ }^{[6]}$ The functionality of $106 \mathrm{CHCs}$ and DHs was assessed with respect to their ability to provide these emergency services. No CHC could provide all seven BEmONC functions, and only $48 \%$ of the DHs could provide all nine of the CEmONC services. ${ }^{[7]}$ Shortage of staff was often cited as the reason for this. During this survey, the maternity staffing was also assessed. The number of midwives (defined as professional nurses with midwifery and advanced midwives) that the unit manager reported were working in the labour ward only or, if not applicable, in the maternity unit was used as the figure for the calculations. Where the personnel were not exclusively allocated to the maternity unit, the number of nurses allocated to the unit per day was used.

\section{Staffing norms for maternity units}

The Guidelines for Maternity Care in South Africa ${ }^{[8]}$ state that to manage a pregnant woman with no risk factors in the active phase of labour, the fetal heart rate and the woman's contractions should be observed every half hour; the blood pressure and pulse should be measured every hour; and every 2 hours the urine output should be measured and urine tested for proteins and ketones, and a vaginal examination should be performed to assess cervical dilation and progress of labour. These required observations indicate that every woman in labour is treated the same as a high-care patient in any setting. This is 
Table 1. Allocation of midwives (professional nurses with midwifery and advanced midwives) to maternity units per district

\begin{tabular}{|c|c|c|c|c|c|}
\hline District & $\begin{array}{l}\text { DHIS births } \\
\text { (2011), } n\end{array}$ & $\begin{array}{l}\text { Midwives per } \\
\text { district, } n\end{array}$ & $\begin{array}{l}\mathrm{WHO}^{[9]} \text { estimates } \\
\text { per district, } n\end{array}$ & $\begin{array}{l}\text { Greenfield }^{[10]} \text { estimates } \\
\text { per district, } n\end{array}$ & $\begin{array}{l}\text { Births/midwife/ } \\
\text { year, } n\end{array}$ \\
\hline 1 & 25931 & 300 & 148 & 346 & 86 \\
\hline 2 & 7114 & 59 & 41 & 95 & 121 \\
\hline 3 & 9522 & 72 & 54 & 127 & 132 \\
\hline 4 & 13159 & 118 & 75 & 175 & 112 \\
\hline 5 & 42480 & 263 & 243 & 566 & 162 \\
\hline 6 & 12895 & 125 & 74 & 172 & 103 \\
\hline 7 & 16811 & 128 & 96 & 224 & 131 \\
\hline 8 & 18209 & 170 & 104 & 243 & 107 \\
\hline 9 & 12383 & 141 & 71 & 165 & 88 \\
\hline 10 & 16493 & 173 & 94 & 220 & 95 \\
\hline 11 & 7658 & 61 & 44 & 102 & 126 \\
\hline 12 & 18569 & 275 & 106 & 248 & 68 \\
\hline
\end{tabular}

Table 2. Structure of maternity staffing at the 12 core district facilities (professional nurses with midwifery and advanced midwives only)

\begin{tabular}{|c|c|c|c|c|c|}
\hline \multirow[b]{2}{*}{ Type of facility } & \multicolumn{4}{|c|}{ Staffing structure } & \multirow[b]{2}{*}{$\begin{array}{l}\text { Total } \\
N(\%)\end{array}$} \\
\hline & $\begin{array}{l}\text { Dedicated labour } \\
\text { ward staff } \\
n(\%)\end{array}$ & $\begin{array}{l}\text { Rotation of staff through } \\
\text { maternity unit but } \\
\text { permanently in unit for a } \\
\text { while before rotation } \\
n(\%)\end{array}$ & $\begin{array}{l}\text { Staff working in all areas } \\
\text { of hospital and allocated } \\
\text { to maternity on a daily } \\
\text { basis } \\
n(\%)\end{array}$ & $\begin{array}{l}\text { Rotation of staff } \\
\text { through maternity, some } \\
\text { permanent, some all areas } \\
\text { of facility } \\
n(\%)\end{array}$ & \\
\hline $\mathrm{CHC}$ & 0 & $14(26.4)$ & $27(50.9)$ & $12(22.6)$ & $53(100.0)$ \\
\hline $\mathrm{DH}$ & $4(6.3)$ & $39(61.9)$ & $9(14.3)$ & $11(17.5)$ & $63(100.0)$ \\
\hline $\mathrm{RH}$ & $6(46.2)$ & $7(53.8)$ & 0 & 0 & $13(100.0)$ \\
\hline PT & $4(100.0)$ & 0 & 0 & 0 & 4 \\
\hline Total & 14 & 60 & 36 & 23 & 133 \\
\hline
\end{tabular}

entirely appropriate, as a pregnancy can only be regarded as low risk after the first 72 hours after birth. Importantly, this implies that the professional nurse with midwifery looking after the patient can do nothing other than monitor that patient, and perhaps another patient in labour in the same area.

Currently most CHCs are staffed by professional nurses with midwifery. Performing an assisted delivery (vacuum delivery) is not in the scope of practice of professional nurses with midwifery, but is part of the skills set of advanced midwives. An attendant skilled in vacuum delivery needs to be available in the maternity unit for every shift. This currently implies that an advanced midwife for a $\mathrm{CHC}$ and a doctor or an advanced midwife for a DH must be available all the time in these facilities.

To cover every shift at advanced midwifery level, there need to be five advanced midwives employed at the site (taking off-duty time, vacation, sick leave, etc. into account). If a pregnant woman needs to be referred to a $\mathrm{DH}$, she must to be accompanied by a professional nurse with midwifery. Again, to ensure proper coverage for 24 hours a day there need to be five such professional nurses. A safe maternity service in a $\mathrm{CHC}$ therefore requires five advanced midwives and five professional nurses with midwifery. I have called this the ideal critical mass of professional nurses, but it is unattainable at present as there are far too few advanced midwives to cover the CHCs. The minimum critical mass of staff, for practical purposes, requires a professional nurse with an assistant nurse or staff nurse always to be present in the maternity unit.

If the ideal critical mass of ten professional nurses is employed, cost-effectiveness requires them to have an adequate workload. Most CHCs and midwife obstetric units (MOUs) refer about a third of women who present to them in labour according to the prescribed referral criteria. The $\mathrm{WHO}^{[9]}$ recommends that each midwife should conduct 175 deliveries per year to ensure cost-effectiveness. In terms of $\mathrm{CHCs}$, and given the intrapartum referral rate, a $\mathrm{CHC}$ midwife conducting approximately 120 deliveries per year would be cost-effective. This implies that a CHC operating a maternity service, or an MOU, must carry out about 1200 deliveries per year to be safe and costeffective. This is called the ideal minimum births per year - WHO.

Greenfield $^{[10]}$ used a formula of 16 midwives per 100 deliveries per month, i.e. 16 midwives per 12000 births per year or 75 births per midwife per year. (These midwives would also manage the babies in the nursery, and antenatal and any postnatal patients.) Given that approximately a third of pregnant women are referred in labour, the minimum number of births per CHC per year would be about 500. This is called the ideal minimum births per year - Greenfield. If a realistic view is taken, a professional nurse with an assistant nurse or staff nurse should manage 600 births (realistic minimum births - WHO) or 250 births (realistic minimum births - Greenfield) per year.

A similar exercise can be conducted for DHs. They would also require ten professional nurses; five do not have to be advanced midwives, as there are doctors available 24 hours a day. However, as doctors perform CSs there should be at least two professional nurses and a staff 
nurse per shift. Since the DH performs CSs, its referral out to regional or tertiary hospitals will be less frequent. Hence, to be safe and cost-effective, DHs would need to perform between 500 (Greenfield) $^{[10]}$ and 1200 $(\mathrm{WHO})^{[9]}$ deliveries per year. There should also always be a minimum of two doctors on call (one for anaesthesia and one for the surgery), so that CSs may be performed on a 24-hours-a-day, 7-days-a-week basis. The first assistant would need to be a professional nurse or a clinical associate.

These staffing norms were applied to the 12 districts in the baseline survey. ${ }^{[7]}$ The total professional nurse personnel per district allocated to maternity care was in excess of the $\mathrm{WHO}^{[9]}$ norm of 175 births per midwife per year in all districts (Table 1); however, when Greenfield's ${ }^{[10]}$ estimates were used, all districts except one had a shortage of midwives.

The staffing structure for the various levels of care is shown in Table 2. The allocation of staff differed per level of care and within each level of care. In the CHCs all staff rotated, some being allocated to maternity for a day only, and others for a longer period.

Tables 3 and 4 give the distribution of births in the 53 CHCs and 63 DHs. Only nine CHCs (18.8\%) performed more than the minimum number of deliveries using the ideal minimum births - WHO norm, while 21 (45.7\%) performed more deliveries than the ideal minimum births - Greenfield norm. If a realistic approach is taken with one midwife and one auxiliary nurse, 18 CHCs (37.6\%) met the WHO norm and $33(68.7 \%)$ met the Greenfield norm.

Seventy-six per cent of the DHs met the ideal minimum number of births with regard to the ideal minimum births - WHO norm and $82.5 \%$ met the ideal minimum births - Greenfield norm.

\begin{tabular}{ll}
\multicolumn{2}{l}{ Table 3. Distribution of births in CHCs $^{*}$} \\
\hline Births per year, $\boldsymbol{N}$ & $\boldsymbol{n}$ (\%) \\
\hline$<250$ & $15(31.3)$ \\
$250-499$ & $12(25.0)$ \\
$500-599$ & $3(6.3)$ \\
$600-1199$ & $9(18.8)$ \\
$>1200$ & $9(18.8)$ \\
Total & $48(100.0)$ \\
*5 CHCs had no data in the District Health Information \\
Service.
\end{tabular}

Table 4. Distribution of births in DHs

\begin{tabular}{ll}
\hline Births per year, $\boldsymbol{N}$ & $\boldsymbol{n}(\%)$ \\
\hline$<500$ & $11(17.5)$ \\
$500-1199$ & $4(6.3)$ \\
$>1200$ & $48(76.2)$ \\
Total & $63(100.0)$
\end{tabular}

Fig. 1 is a scatter plot of the number of midwives (professional nurses with midwifery and advanced midwives) against the number of births per year. Four CHCs have been removed from Fig. 1 because they performed more than 2000 deliveries per year (namely 2 050, 2 141, 2198 and 3544 deliveries). The solid line represents the ideal minimum births per year and the dashed-dotted line the realistic minimum births per year using the $\mathrm{WHO}$ norms. The dashed line represents the ideal minimum births per year and the dotted line the realistic minimum births per year using Greenfield's norms. The ideal critical mass of staff is the number of midwives needed to run a unit safely. The minimum critical mass is the minimum number of midwives (professional nurses with midwifery and advanced midwives) to run a unit safely. In this group, it is assumed that the professional nurse will have a staff nurse or nursing assistant in attendance.

There were $22 \mathrm{CHCs}$ (45.8\%) with less than ten midwives in the maternity unit (the ideal

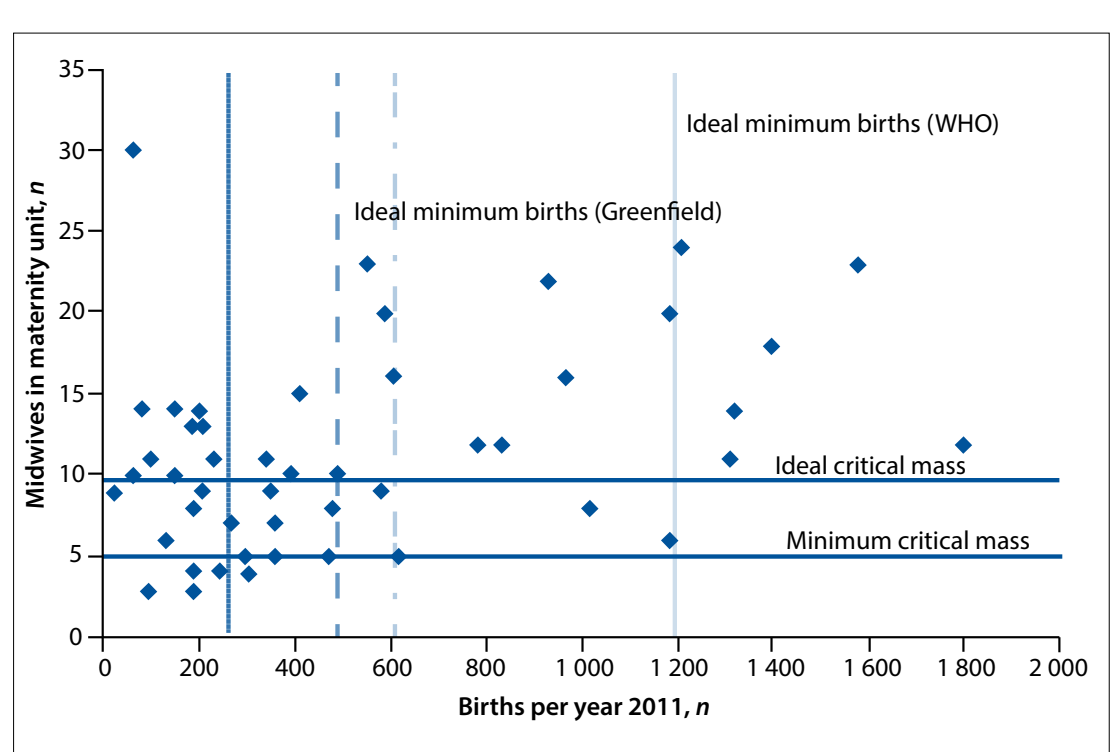

Fig. 1. Comparison of midwives in maternity units of CHCs and births per year.

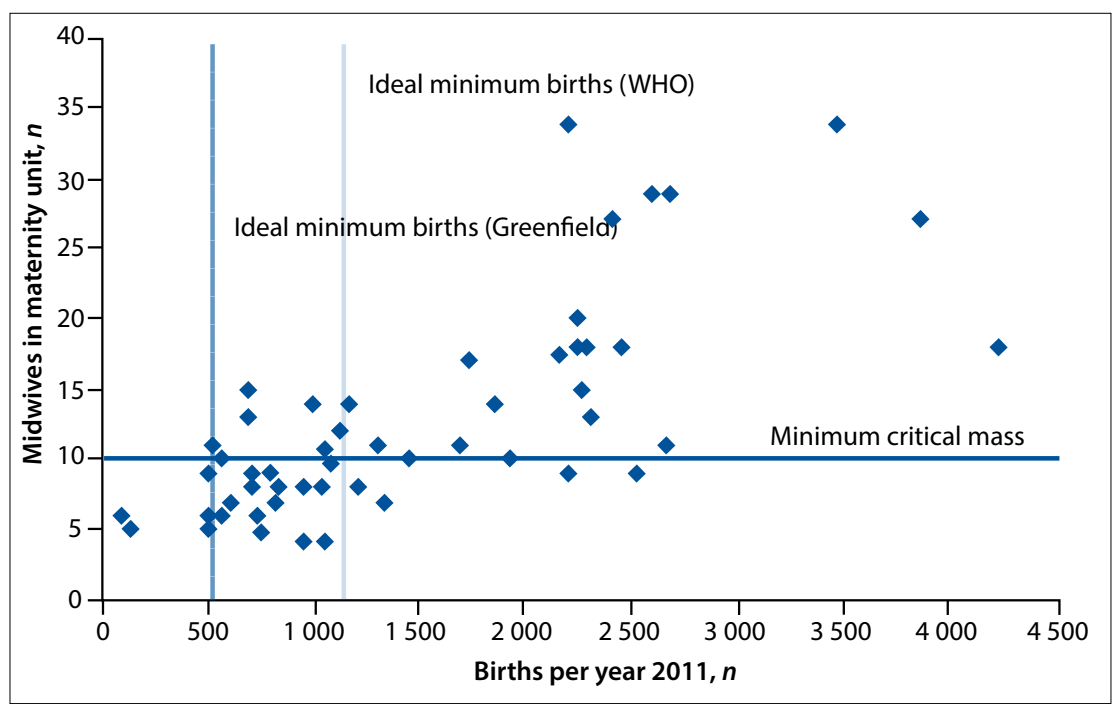

Fig. 2. Comparison of midwives in maternity units of DHs and births per year.

minimum critical mass), making these $\mathrm{CHCs}$ theoretically unsafe. If the realistic minimum critical mass of staff (i.e. five midwives and five auxiliary nurses) is used, five $\mathrm{CHCs}$ (10.4\%) fall below this critical mass. Overall, $20(41.7 \%)$ and 16 (33.3\%) CHCs had less than the ideal minimum births and ideal critical mass of midwives using the WHO and Greenfield norms, respectively. Interestingly, 13 of $\mathrm{CHCs}$ (27.1\%) had more than the ideal critical mass of staff but fewer than the ideal minimum number of births, and 15 (31.3\%) had more than the ideal critical mass of staff and ideal minimum of births using Greenfield's norms. Eighteen CHCs (37.8\%) had more than the ideal critical mass of staff but fewer than the ideal minimum number of births, and 10 CHCs (20.1\%) had more than the ideal critical mass of staff and ideal minimum of births using the WHO norms.

Fig. 2 is a scatter plot of the number of midwives in maternity units against the number of births in the DHs. One $\mathrm{DH}$, 
having 5827 births and 28 midwives, was excluded from the scatter plot in Fig. 2. The solid vertical line represents the ideal minimum births per $\mathrm{DH}$ using the WHO norm and the dashed line the ideal minimum births per DH using Greenfield's norm. Thirty-one DHs (49.2\%) had less than the minimum critical mass of midwives to run their maternity unit safely. Twenty-two (34.9\%) and 10 (15.9\%) DHs had less than the ideal minimum number of births using the WHO and Greenfield norms, respectively. Six DHs (1.0\%) had a more than minimum critical mass of midwives but less than the ideal minimum number of births, and $18 \mathrm{DHs}(28.6 \%)$ had more than the minimum critical mass of midwives and the ideal minimum number of births using the WHO norm. If the Greenfield norms are used, no DH had less than the ideal minimum number of births and more than the minimum critical mass of midwives, whereas 26 DHs (41.3\%) had both more than the minimum critical mass of midwives and the ideal minimum number of births.

\section{Healthcare facilities and the population}

The Council for Scientific and Industria Research (CSIR) Guidelines for the Provision of Social Facilities in South African Settlements ${ }^{[11]}$ is a guideline document that 'seeks to provide a quantitative and rational framework for the provision of key social facilities for various levels of settlements to support the planning process and provide support to the social facility investment plans. The norms given in this guideline are a level 3 hospital per 2.4 million population, a regional hospital (RH) per 1.77 million population (level 2), a DH per 300000 900000 population with an access distance of $30 \mathrm{~km}$ (level 1), a CHC for every 60000 140000 population with $90 \%$ access distance of $5 \mathrm{~km}$, and a primary healthcare clinic for every 40000 population with an access distance of $5 \mathrm{~km}$. Using these figures and those of mid-year Stats SA population estimates for $2013,{ }^{[12]}$ it can be suggested that $\mathrm{SA}$ should have:

- 22 tertiary hospitals - level 3 (we have 22)

- 30 RHs - level 2 (we have 42)

- Between 59 and 177 DHs - level 1 (we have 188).

The number of CHCs and hospitals in each district was counted and an estimation made of the theoretical population based on the United Nations (UN) formula ${ }^{[6]}$ that could be served by that number of institutions. This is similar to the CSIR report. ${ }^{[11]}$ In all 12 districts there was an excess of maternity units for the population served (Table 5).

Table 5. Healthcare facilities, population and UN recommendations for emergency obstetric care

\begin{tabular}{|c|c|c|c|c|c|c|c|c|}
\hline District & $\mathrm{CHC}$ & DH & RH & PT & Total & $\begin{array}{l}\text { District } \\
\text { population }\end{array}$ & $\begin{array}{l}\text { Population } \\
\text { that could } \\
\text { be served }^{\star}\end{array}$ & $\begin{array}{l}\text { 'Excess } \\
\text { capacity' }\end{array}$ \\
\hline 1 & 9 & 12 & 1 & 1 & 23 & 1806831 & 6000000 & 4193169 \\
\hline 2 & 0 & 4 & 1 & 0 & 5 & 499875 & 2000000 & 1500125 \\
\hline 3 & 0 & 5 & 1 & 0 & 6 & 694198 & 2500000 & 1805802 \\
\hline 4 & 1 & 10 & 1 & 0 & 12 & 767678 & 5000000 & 4232322 \\
\hline 5 & 7 & 1 & 4 & 1 & 13 & 2965602 & 3000000 & 34398 \\
\hline 6 & 3 & 3 & 1 & 0 & 7 & 760648 & 2000000 & 1239352 \\
\hline 7 & 4 & 2 & 1 & 1 & 8 & 1058086 & 2000000 & 941914 \\
\hline 8 & 3 & 6 & 1 & 0 & 10 & 965950 & 3500000 & 2534050 \\
\hline 9 & 2 & 8 & 0 & 0 & 10 & 666664 & 4000000 & 3333336 \\
\hline 10 & 6 & 8 & 1 & 0 & 15 & 943137 & 4500000 & 3556863 \\
\hline 11 & 4 & 2 & 0 & 1 & 7 & 375167 & 1500000 & 1124833 \\
\hline \multirow[t]{2}{*}{12} & 16 & 3 & 1 & 0 & 20 & 1400000 & 2000000 & 600000 \\
\hline & 55 & 64 & 13 & 4 & 136 & & & \\
\hline
\end{tabular}

there should be at least one comprehensive and four basic emergency obstetric care facilities.

Table 6. Estimated number of deliveries per year according to birth-weight categories and levels of care

\begin{tabular}{llllll}
\hline & CHC & DH & RH & PT & NC \\
\hline $\begin{array}{lllll}\text { All births, } n \\
500-999 \mathrm{~g}\end{array}$ & 748 & 3108 & 4087 & 2027 & 2660 \\
$1000-1499 \mathrm{~g}$ & 1122 & 4663 & 5529 & 2962 & 3239 \\
$1500-1999 \mathrm{~g}$ & 2431 & 9325 & 9616 & 4365 & 4338 \\
$2000-2499 \mathrm{~g}$ & 13091 & 31084 & 23318 & 8652 & 7172 \\
$\geq 2500 \mathrm{~g}$ & 169616 & 340373 & 197842 & 59861 & 40427 \\
Total & 187007 & 388554 & 240392 & 77867 & 57835 \\
Perinatal deaths, $n$ & & & & & \\
$500-999 \mathrm{~g}$ & 460 & 2509 & 3083 & 1362 & 1461 \\
$1000-1499 \mathrm{~g}$ & 284 & 2159 & 1863 & 819 & 731 \\
$1500-1999 \mathrm{~g}$ & 260 & 1728 & 1377 & 655 & 506 \\
$2000-2499 \mathrm{~g}$ & 255 & 1551 & 1252 & 504 & 360 \\
$\geq 2500 \mathrm{~g}$ & 560 & 3948 & 2730 & 952 & 663 \\
$\quad$ Total & 1819 & 11896 & 10305 & 4292 & 3721 \\
PT = provincial tertiary hospital; NC = national central hospital. & & & & \\
& & & & &
\end{tabular}

\section{Deliveries per site per level of care in SA}

The numbers of births per birth-weight category and level of care were calculated using the number of births recorded per level of care in the District Health Information Service for $2012-2013$ and annualised. ${ }^{[13]}$ This is shown in Table 6.

The Regulation Gazette of $2011^{[14]}$ listed 188 DHs, 42 RHs, 12 provincial tertiary hospitals and 10 national central hospitals. Table 7 gives the estimated average number of births and early neonatal deaths (ENNDs) per institution.
Most deaths occur in DHs, as do most births. The mortality rates in the $\mathrm{DHs}$ are the highest, but one $\mathrm{DH}$ delivering an average of 2000 babies per year will deliver a liveborn baby weighing between $1000 \mathrm{~g}$ and $1999 \mathrm{~g}$ once every 5 days, and 12\% (one in eight) will be an ENND. If the hospital delivery rate is 500 births per year, a liveborn baby weighing between $1000 \mathrm{~g}$ and $1999 \mathrm{~g}$ will be delivered every 20 days and two will die. This analysis raises the question of what resources should be available in each institution and how many deliveries per year will make the institution cost-effective, 
Table 7. Average number of births, stillbirths, live births, stillbirths and ENNDs per level of care and birth-weight category

\begin{tabular}{|c|c|c|c|c|}
\hline & DH & RH & PT & NC \\
\hline South Africa - hospitals per level of care, $n$ & 188 & 42 & 12 & 10 \\
\hline \multicolumn{5}{|l|}{ Average births per year per hospital, $n$} \\
\hline $500-999 \mathrm{~g}$ & 17 & 97 & 169 & 266 \\
\hline $1000-1499 \mathrm{~g}$ & 25 & 132 & 247 & 324 \\
\hline $1500-1999 \mathrm{~g}$ & 50 & 229 & 364 & 434 \\
\hline $2000-2499 g$ & 165 & 555 & 721 & 717 \\
\hline$\geq 2500 \mathrm{~g}$ & 1810 & 4711 & 4988 & 4043 \\
\hline Total & 2067 & 5724 & 6489 & 5784 \\
\hline \multicolumn{5}{|l|}{ Average stillbirths per hospital per year, $n$} \\
\hline $500-999 \mathrm{~g}$ & 8 & 46 & 72 & 95 \\
\hline $1000-1499 \mathrm{~g}$ & 7 & 29 & 47 & 48 \\
\hline $1500-1999 \mathrm{~g}$ & 7 & 26 & 43 & 38 \\
\hline $2000-2499 \mathrm{~g}$ & 6 & 23 & 34 & 27 \\
\hline$\geq 2500 \mathrm{~g}$ & 13 & 49 & 58 & 41 \\
\hline Total & 42 & 173 & 254 & 248 \\
\hline \multicolumn{5}{|l|}{ Average live births per hospital per year, $n$} \\
\hline $500-999 \mathrm{~g}$ & 16 & 94 & 162 & 255 \\
\hline $1000-1499 \mathrm{~g}$ & 24 & 128 & 237 & 310 \\
\hline $1500-1999 \mathrm{~g}$ & 49 & 222 & 349 & 415 \\
\hline $2000-2499 g$ & 162 & 538 & 693 & 686 \\
\hline$\geq 2500 \mathrm{~g}$ & 1774 & 4568 & 4793 & 3869 \\
\hline Total & 2025 & 5551 & 6234 & 5536 \\
\hline \multicolumn{5}{|l|}{ Average ENNDs per hospital per year, $n$} \\
\hline $500-999 \mathrm{~g}$ & 10 & 50 & 70 & 76 \\
\hline $1000-1499 \mathrm{~g}$ & 6 & 19 & 25 & 29 \\
\hline $1500-1999 \mathrm{~g}$ & 3 & 8 & 13 & 13 \\
\hline $2000-2499 g$ & 2 & 7 & 8 & 9 \\
\hline$\geq 2500 \mathrm{~g}$ & 7 & 16 & 20 & 24 \\
\hline Total & 28 & 99 & 136 & 152 \\
\hline
\end{tabular}

while at the same time keeping healthcare accessible to the population.

\section{Discussion}

Part of the explanation for the poor functionality with respect to emergency obstetric care in the $\mathrm{CHCs}$ and $\mathrm{DHs}$ relates to the number of facilities and the staffing of these facilities: (i) according to the UN norms ${ }^{[6]}$ and CSIR norms, ${ }^{[11]}$ there are too many healthcare facilities for the population served, yet there is sufficient staff to manage the births in the district; (ii) there are some maternity units that are clearly unsafe given the number of staff allocated to the unit (less than the ideal minimum critical mass or realistic minimum critical mass of midwives in the case of CHCs); and (iii) there are a number of maternity units that perform fewer than the minimum number of deliveries, making them both unsafe and not cost-effective.
To maintain skills, a midwife needs to perform deliveries regularly - doing one delivery a month is insufficient. The Guidelines for Maternity Care in South Africa ${ }^{[8]}$ clearly stipulate the observations required for a 'lowrisk' woman in labour, and these are such that during the active phase of labour the woman must be observed at least every half hour. This implies that the professional nurse cannot do anything else during that labour, other than perhaps monitor another woman in labour. In essence, a woman in labour requires monitoring at the same level as any patient in a high-care setting. This is appropriate, as there is not the knowledge to predict accurately before labour begins which woman or fetus will develop complications during the labour. However, given human resources of professional nurses in many $\mathrm{CHCs}$ and limitations and the multiple tasks required
DHs, it is impossible for them to fulfil these requirements in their maternity units. Such maternity units then become unsafe.

The two norms used, namely the $\mathrm{WHO}^{[9]}$ and Greenfield ${ }^{[10]}$ norms, are two extremes, and happily most of SA's maternity units fall somewhere in between. The WHO norm ${ }^{[9]}$ is the minimum number of professional nurses required to provide a maternity service. Greenfield's norms ${ }^{[10]}$ have been developed with SA circumstances in mind and are viewed as the ideal, even if unattainable at present.

The solution to making maternity units safer and more cost-effective is to realign services, which implies reorganisation of services so that there are properly functioning, safe maternity units open 24 hours a day, 7 days a week. However, this will make the maternity services less accessible unless there is a system for the efficient and rapid transfer of emergency cases. The maternity waiting areas could become a valuable mechanism for ensuring that the woman is at a safe maternity unit at the time of her labour.

Realignment of services and improved emergency transport are not impossible to achieve, as demonstrated by the example of the Free State Province, where maternal mortality was halved by improving the province's interfacility transport by providing dedicated maternity care ambulances, improving the knowledge and skills of the provincial staff and consolidating the CS services. ${ }^{[15]}$

1. Rosenfield $A$, Maine D. Maternal mortality - a neglected tragedy: Where is the M in MCH? Lancet 1985;2(8446):83-85
[http://dx.doi.org/10.1016/S0140-6736(85)90188-6]

2. Birthplace in England Collaborative Group. Perinatal and maternal outcomes by planned place of birth for healthy women with low risk pregnancies: The Birthplace in England national prospective cohor study. BMJ 2011;343:d7400. [http://dx.doi.org/10.1136/bmj.d7400] 3. Michalow J, Chola L, McGee S, et al. Triple return on investment: The cost and impact of 13 interventions that could prevent stillbirths and save the lives of mothers and babies in South Africa. BMC Pregnancy Childbirth 2015;15:9. [http://dx.doi.org/10.1186/s12884-015-0456-9] LiST: The Lives Saved Tool. An evidence-based tool for LiST: The Lives Sased tool for estimating intervention impact. http://www.jhsph.edu/dept/ih/
IIP/list/index.html (accessed 26 February 2015). 5. Boschi-Pinto C, Black RE. Development and use of the Lives Saved Tool: A model to estimate the impact of scaling up proven interventions Tool: A model to estimate the impact of scaling up proven interventions
on maternal, neonatal and child mortality. Int J Epidemiol on maternal, neonatal and child mortality. Int J Epidemic 2011:40(2):520-521. [http://dx.doi.org/10.1093/ije/dyq171]

6. UNICEF, WHO, UNFPA. Guidelines for Monitoring the Availability and Use of Obstetric Services. New York: United Nations Children's Fund, 1997

7. Pattinson RC, Makin JD, Pillay Y, van den Broek N, Moodley J. Basic and comprehensive emergency obstetric and neonatal care in 12 South African health districts. S Afr Med 2015;105(4):256-260. [http://dx.doi.org/10.7196/SAMJ.9181]

. Guidelines for Maternity Care in South Africa. http://www. health.gov.za/policies.php (accessed 17 June 2014).

9. Newborns: No longer going unnoticed. In: The World Health Report: 2005: Make Eveing unnoticed. In. The World Health WHO Press. 2005:79-102

Greenfield DH. Midwifery staffing needs in a maternity ward. Presented at the 25th Conference on Priorities in Perinatal Care in South Africa, Drakensberg, KwaZulu-Natal, 7-10 March 2006. 11. Council for Scientific and Industrial Research. CSIR Guidelines for the Provision of Social Facilities in South African Settlements. 1st ed. Pretoria: CSIR, 2012.

2. Statistical Release P0302. Mid-year population estimates 2013. Statistics South Africa, May 2013

13. Pattinson RC, Rhoda N. Saving Babies 2012-2013: Ninth Report on Perinatal Care in South Africa. Pretoria: Tsephega Press, 2014. 14. Regulation Gazette No. 34521 of 12 August 2011, vol. 553, No 9570[1]

15. Schoon M. Impact of inter-facility transport on matern mortality in the Free State Province.S Afr Med J 2013:103(8):534537. [http://dx.doi.org/10.7196/SAMJ.6828] Accepted 24 November 2014 